Article

\title{
Investigation of the Pressure Dependent Hydrogen Solubility in a Martensitic Stainless Steel Using a Thermal Agile Tubular Autoclave and Thermal Desorption Spectroscopy
}

\author{
Patrick Fayek $^{1,+}{ }^{\text {, Sebastian Esser }}{ }^{2,+}$, Vanessa Quiroz ${ }^{1,+}$ and Chong Dae Kim ${ }^{2, *,+, \ddagger}$ \\ 1 Robert Bosch GmbH - Corporate Sector Research and Advance Engineering, 71272 Renningen, Germany; \\ Patrick.Fayek@de.bosch.com (P.F.); Vanessa.Quiroz@de.bosch.com (V.Q.) \\ 2 Technische Hochschule Köln, 50679 Köln, Germany; sebastian.esser@ymail.com \\ * Correspondence: chong.kim@th-koeln.de; Tel.: +49-221-8275-2947 \\ + These authors contributed equally to this work. \\ ‡ Current address: Technische Hochschule Köln, Campus Deutz, Betzdorfer Straße 2, 50679 Köln, Germany.
}

\section{check for}

updates

Citation: Fayek, P.; Esser, S.; Quiroz, V.; Kim, C.D. Investigation of the Pressure Dependent Hydrogen Solubility in a Martensitic Stainless Steel Using a Thermal Agile Tubular Autoclave and Thermal Desorption Spectroscopy. Metals 2021, 11, 231. https://doi.org/10.3390/met11020231

Academic Editors: Jacques Huot and Thorsten Michler

Received: 13 December 2020

Accepted: 21 January 2021

Published: 29 January 2021

Publisher's Note: MDPI stays neutral with regard to jurisdictional clai-ms in published maps and institutio-nal affiliations.

Copyright: (C) 2021 by the authors. Licensee MDPI, Basel, Switzerland. This article is an open access article distributed under the terms and conditions of the Creative Commons Attribution (CC BY) license (https:// creativecommons.org/licenses/by/ $4.0 /)$.
Abstract: Hydrogen is nowadays in focus as an energy carrier that is locally emission free. Especially in combination with fuel-cells, hydrogen offers the possibility of a $\mathrm{CO}_{2}$ neutral mobility, provided that the hydrogen is produced with renewable energy. Structural parts of automotive components are often made of steel, but unfortunately they may show degradation of the mechanical properties when in contact with hydrogen. Under certain service conditions, hydrogen uptake into the applied material can occur. To ensure a safe operation of automotive components, it is therefore necessary to investigate the time, temperature and pressure dependent hydrogen uptake of certain steels, e.g., to deduct suitable testing concepts that also consider a long term service application. To investigate the material dependent hydrogen uptake, a tubular autoclave was set-up. The underlying paper describes the set-up of this autoclave that can be pressurised up to $20 \mathrm{MPa}$ at room temperature and can be heated up to a temperature of $250{ }^{\circ} \mathrm{C}$, due to an externally applied heating sleeve. The second focus of the paper is the investigation of the pressure dependent hydrogen solubility of the martensitic stainless steel 1.4418. The autoclave offers a very fast insertion and exertion of samples and therefore has significant advantages compared to commonly larger autoclaves. Results of hydrogen charging experiments are presented, that were conducted on the Nickel-martensitic stainless steel 1.4418. Cylindrical samples $3 \mathrm{~mm}$ in diameter and $10 \mathrm{~mm}$ in length were hydrogen charged within the autoclave and subsequently measured using thermal desorption spectroscopy (TDS). The results show how hydrogen sorption curves can be effectively collected to investigate its dependence on time, temperature and hydrogen pressure, thus enabling, e.g., the deduction of hydrogen diffusion coefficients and hydrogen pre-charging concepts for material testing.

Keywords: hydrogen uptake; gaseous hydrogen; hydrogen sorption curves; thermal desorption spectroscopy; martensitic stainless steel; autoclave

\section{Introduction}

In terms of the energy transformation, it is not sufficient to develop only technologies for sustainable energy production, but also technologies for energy storage or conversion. In this context, hydrogen is an excellent energy carrier. It reacts with oxygen residue-free to water and has a climate-neutral energy balance, if it is produced with energy from sustainable sources [1].

Taking into account that a FCEV (fuel-cell-electric-vehicle) can be fuelled within minutes [2] and it only emits water, it offers significant advantages.

In fuel-cell-vehicles, components are in contact with either dry or wet hydrogen gas [3]. Many of the components alongside the hydrogen path or the anode path will be at least partly made of steels. 
Unfortunately, steels under the application of hydrogen may show an effect that is known in the literature as hydrogen embrittlement [4-9]. Hydrogen embrittlement can appear as a reduction of the ductility of the materials as well as a reduction of the fatigue lifetime $[9,10]$. To ensure a safe and reliable operation of steel components in fuel-cellvehicles, the material properties under hydrogen embrittling conditions have to be known. In addition to the embrittlement caused by external hydrogen, internal hydrogen accordingly deteriorates the materials behaviour [11]. Since steels show a certain hydrogen absorption capacity, the internal hydrogen has to be accounted for as well.

Hydrogen can diffuse into the material especially during long-term exposure, which is implied by the components application. To investigate the materials hydrogen uptake, an autoclave concept was established that offers the possibility to effectively analyse different materials under hydrogen pressures and temperatures regarding their hydrogen uptake. Hydrogen pre-charging concepts can thus be deducted and the material behaviour can be investigated under supposedly worst case conditions. The main requirement on the autoclave was to ensure a rapid loading and unloading of the samples, in order to be able to capture the hydrogen content in the equilibrium conditions regarding applied temperature and pressure. This is necessary since hydrogen is a fast diffusing species. Especially in ferritic and martensitic steels [12], hydrogen effusion from samples has been reported for larger autoclave setups caused by long cooling times [13,14].

Subsequent to the sample charging, the hydrogen contents are measured using thermal desorption spectroscopy (TDS) applied with a mass spectrometer. The apparatus used for TDS measurements is located at the Max Planck Institute for Intelligent Systems (MPI-IS) in Stuttgart and is described elsewhere [15].

This paper presents the apparatus, exhibiting an agile thermal behaviour and thus ensuring to minimise hydrogen effusion, as well as the hydrogen solubilities for the martensitic stainless steel 1.4418 in dependence of pressure, time and temperature. Diffusion coefficients are evaluated based on the investigations and the results are discussed in light of available data in the literature. With this approach, the hydrogen sorption behaviour for the hydrogen uptake can be investigated, e.g., to deduct pre-charging concepts for mechanical tests. Pre-charging is necessary to account for long-term exposure or runtime in hydrogen atmosphere. The material behaviour under application near conditions can be investigated, thus enabling safe and efficient component design for applications under hydrogen [16].

\section{Investigated Material}

The material investigated in this study is the stainless nickel-martensitic low carbon steel 1.4418. It is investigated in the QT900 condition, for which the mechanical properties are displayed in Table 1. Displayed are the values measured in air and under $1 \mathrm{MPa}$ hydrogen. It can be seen that the hydrogen compatibility of the material is remarkable under the applied conditions, which makes this steel interesting for applications in gaseous hydrogen.

Table 1. Mechanical properties of the steel 1.4418 in QT900 condition. Given are yield strength (YS), ultimate tensile strength (UTS), elongation to fracture (A), reduction of area (RA) and relative reduction of area (RRA).

\begin{tabular}{cccccc}
\hline Atmosphere & YS [MPa] & UTS [MPa] & A [\%] & RA [\%] & RRA [\%] \\
\hline Air & 834 & 946 & 17.7 & 66.8 & \\
$1 \mathrm{MPa} \mathrm{H}_{2}$ & 826 & 946 & 18.4 & 65.6 & 98.1 \\
\hline
\end{tabular}

The chemical composition is displayed in Table 2. The material was available in bars, already in the QT900 condition, with a diameter of $20 \mathrm{~mm}$. From these bars, samples for the charging experiments were milled with a length of $10 \mathrm{~mm}$ and a diameter of $3 \mathrm{~mm}$. Prior to 
the charging procedure, the samples were cleaned in an ultrasonic bath using cold cleaning solvent, cyclohexan and ethanol successively as cleaning agents.

Table 2. Chemical composition of the steel 1.4418. Values are in wt. \%.

\begin{tabular}{ccccccccc}
\hline $\mathbf{C}$ & $\mathbf{S i}$ & $\mathbf{M n}$ & $\mathbf{P}$ & $\mathbf{S}$ & $\mathbf{C r}$ & $\mathbf{N i}$ & $\mathbf{M o}$ & $\mathbf{N}$ \\
\hline 0.025 & 0.40 & 0.92 & 0.021 & 0.008 & 15.47 & 4.66 & 0.90 & 0.068 \\
\hline
\end{tabular}

The steel is in a quenched and tempered condition and therefore exhibits a martensitic microstructure. The maximum martensite needle lengths were determined to be around $50 \mu \mathrm{m}$ and trace amounts of ferrite were found in metallographic analysis. An image representing the microstructure of the underlying material is displayed in Figure 1.

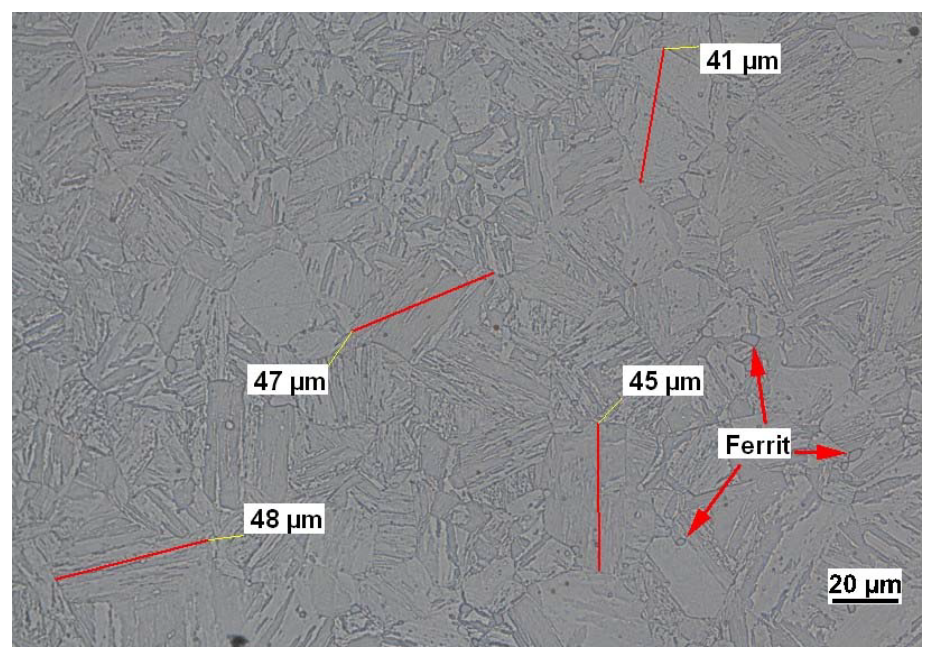

Figure 1. Representative metallographic image of material 1.4418. The image was taken from a sample prepared with V2A-etchant, which consists out of $100 \mathrm{~mL}$ distilled water $+100 \mathrm{~mL}$ concentrated hydrochloric acid $+10 \mathrm{~mL}$ concentrated nitric acid $+0.3 \mathrm{~mL}$ spare stain.

\section{Experimental Procedure}

To be able to realise charging conditions as accurately as possible, especially for materials with high diffusion coefficients, an apparatus for pressurised hydrogen charging is presented, which is characterised by an agile thermal behaviour and short process times. Thereby, the hydrogen effusion after completion of the charging processes can be minimised.

The used apparatus is shown in Figure 2. The loading chamber is realised by a thinwalled stainless steel tube (wall-thickness $1 \mathrm{~mm}$, material type 1.4435) exhibiting a small reactor volume. Ball valves are attached to the ends of the charging tube, which allow a sufficient sealing of the tube during the charging process, as well as enable a fast loading and unloading of the metallic samples. The samples used are $3 \mathrm{~mm}$ in diameter and $10 \mathrm{~mm}$ in length and can be transferred into the tubular autoclave through a ball valve (Ball Valve 1 , see Figure 2). The sample geometry ensures a fast loading and unloading of the sample as well as a fast hydrogen charging. Furthermore, a sample weight of approximately $0.5 \mathrm{~g}$ is sufficient for hydrogen contents to be reliably determined by application of TDS. 


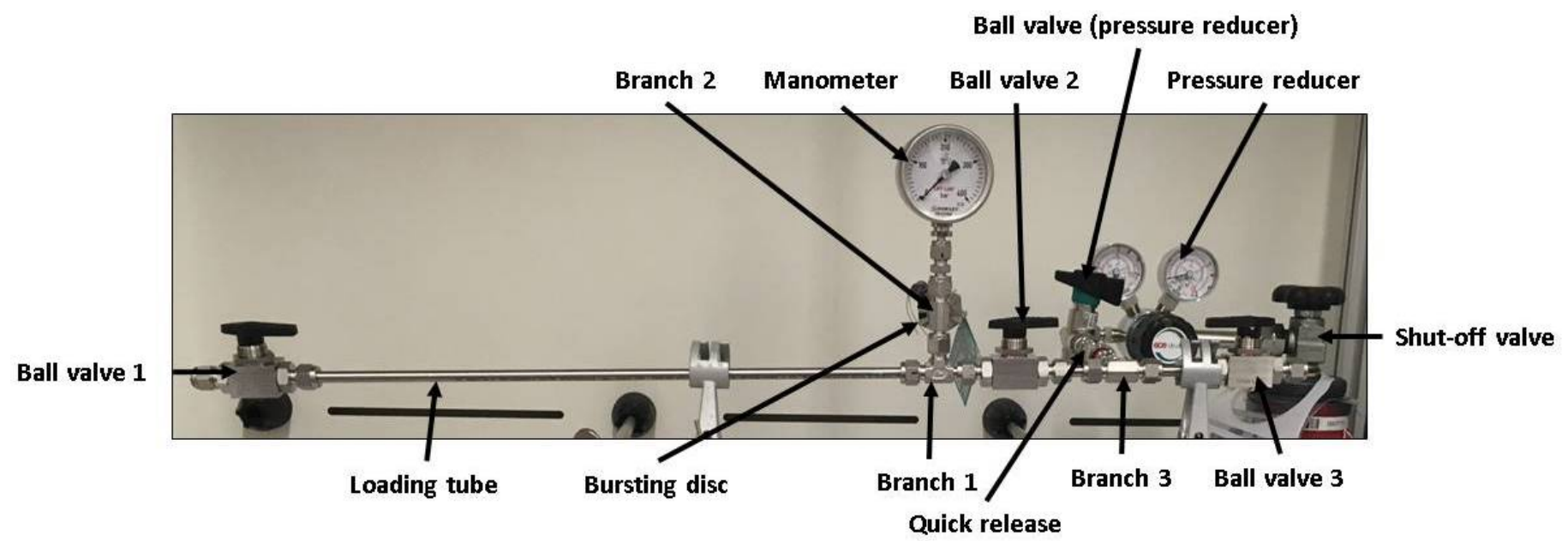

Figure 2. Constructed and used apparatus for the hydrogen charging experiments.

The current pressure in the charging tube is controlled via a pressure gauge and for safety reasons the device is equipped with a bursting disc. A hydrogen gas-bottle is used to apply pressure via a quick connector, which allows disconnecting the device from the gas-bottle during the runtime of the charging experiments. The heating of the charging chamber is realised by a heating sleeve, which is placed in a mid position around the charging tube. The specimens are positioned centrally between Ball Valve 1 and Ball Valve 2 in the loading tube. The autoclave is aligned as horizontally as possible, so that there is a linear contact surface between the outer surface of the specimens and the inner tube wall. Whether this contact surface has an influence on the loading kinetics is not investigated further.

Because the temperature inside the loading tube is not measured during hydrogen charging, a thermal investigation was carried out in advance to evaluate the actual temperature as a function of the heating sleeve temperature. Furthermore, the heating and cooling behaviour as well as the temperature gradient in the tube were investigated. Figure 3 shows the correlation of the measured temperature inside the tube as function of the heating sleeve temperature. In the area of the innermost $50 \mathrm{~mm}$ of the heated tube section, a maximum temperature difference of $2.5^{\circ} \mathrm{C}$ in air temperature was measured at steady state for a target loading temperature of $210^{\circ} \mathrm{C}$.

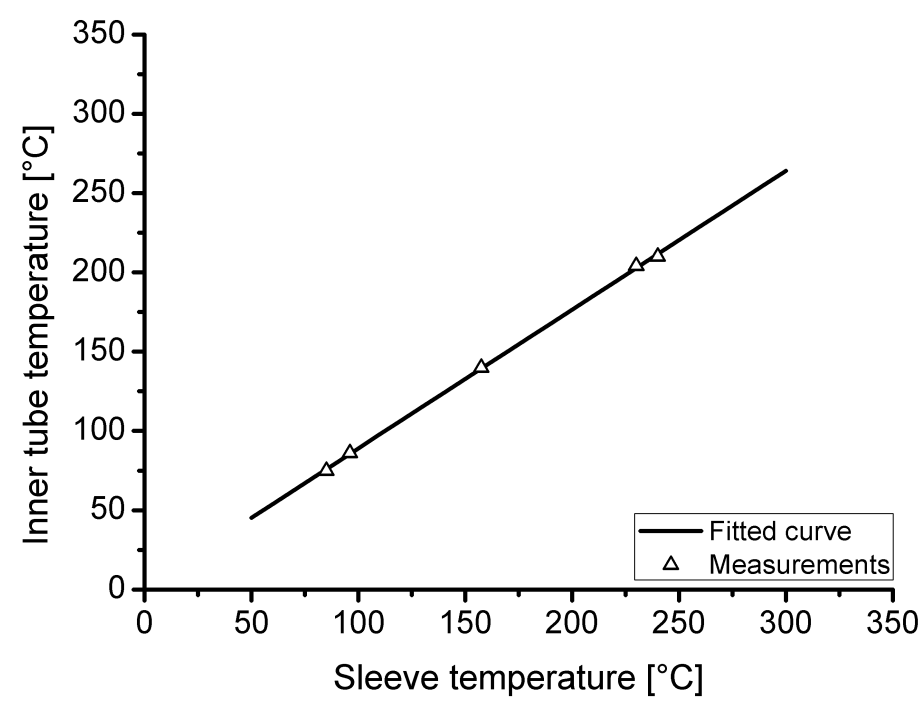

Figure 3. Correlation between heating sleeve temperature and achieved temperature within the tubular autoclave at the centre of the heating sleeve. 
Measured cooling and heating curves for a charging temperature of $200{ }^{\circ} \mathrm{C}$ are displayed in Figure 4. The presented curves and results were recorded in previous reference measurements, in an unpressurised state under ambient conditions (atmospheric pressure, room temperature and air). Figure 4 shows that the heating time from room temperature to $200^{\circ} \mathrm{C}$ is approximately $480 \mathrm{~s}$. The cooling time (with forced cooling) from $200^{\circ} \mathrm{C}$ to less than $30^{\circ} \mathrm{C}$ is around $180 \mathrm{~s}$.

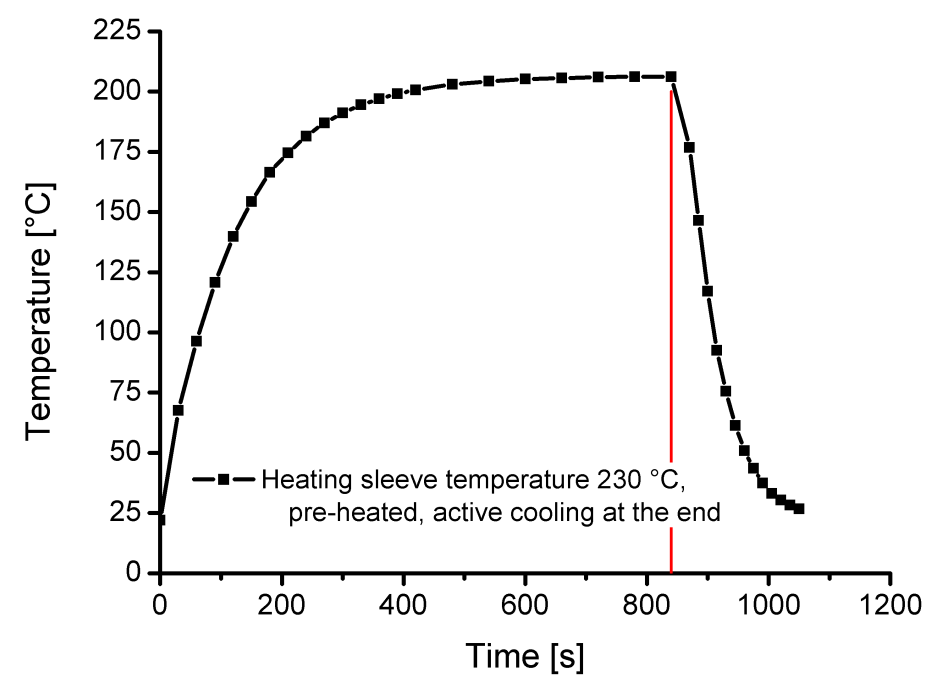

Figure 4. Heating and cooling curve for a charging temperature of $200^{\circ} \mathrm{C}$.

Hydrogen chargings are performed as follows. In one batch, three samples are introduced via a ball valve into the device and placed at a specific position using a magnet. The device is purged with hydrogen gas and then four subsequent pressure purgings are performed from $15 \mathrm{MPa}$ to approximately $1 \mathrm{MPa}$. After the last pressure purging, the desired hydrogen pressure for the charging batch is adjusted. At this point, the (pre-heated) heating sleeve is applied and kept on the tube for the specified time. Once the desired holding time is reached, the cooling process is initiated. Therefore, the heating sleeve is removed and an axial fan is placed directly in front of the charging tube. After sufficient cooling to temperatures below $60^{\circ} \mathrm{C}$, the pressure is relieved from the device and the samples are unloaded. Directly after unloading, the samples are stored in a cryogenic container at approximately $-156^{\circ} \mathrm{C}$, in which the hydrogen charged condition can be preserved. This procedure is repeated for three different pressures with three different long charging times each, so that nine batches are loaded with three samples each. The corresponding charging pressures and charging times are shown in Table 3.

Table 3. Parameters used for the gaseous hydrogen charging of samples of the martensitic stainless steel 1.4418 at a charging temperature of $250^{\circ} \mathrm{C}$ and estimated hydrogen equilibrium concentrations $c_{e q}$ in weight ppm at the indicated pressures.

\begin{tabular}{cccccc}
\hline $\begin{array}{c}\text { Pressure at } \\
\text { RT [MPa] }\end{array}$ & $\begin{array}{c}\text { Pressure at } \\
\mathbf{2 5 0}^{\circ} \mathbf{C}[\mathbf{M P a}]\end{array}$ & $\begin{array}{c}\text { 1st Charging } \\
\text { Duration [s] }\end{array}$ & $\begin{array}{c}\text { 2nd Charging } \\
\text { Duration [s] }\end{array}$ & $\begin{array}{c}\text { 3rd Charging } \\
\text { Duration [s] }\end{array}$ & $\begin{array}{c}\mathbf{c}_{\mathbf{e q}} \\
\text { [wt.-ppm] }\end{array}$ \\
\hline 1 & 1.1 & 3274 & 11,191 & 55,761 & 2.78 \\
6 & 6.7 & 3234 & 10,064 & 55,525 & 5.31 \\
13.5 & 15.0 & 3340 & 9451 & 58,419 & 8.10 \\
\hline
\end{tabular}

Hydrogen content measurements are performed with a TDS device as described in [15], which was calibrated using titanium hydride. The samples are therefore separately taken from the cryogenic container, cleaned and defrosted in isopropanol to avoid ice formation on the sample surface. Afterwards, the samples are dried using a pressurised nitrogen flow and introduced into the TDS device. Once a sufficient vaccuum is achieved, the samples are heated from room temperature to $700^{\circ} \mathrm{C}$ with a heating rate of $0.2 \mathrm{~K} / \mathrm{s}$. The emitted hydrogen is measured via a mass spectrometer and a desorption spectra is 
obtained as function of the temperature as described e.g., in $[15,17]$. To obtain the hydrogen contents the TDS spectra are integrated over temperature. Together with the calibration constant, determined with $\mathrm{TiH}_{2}$, the hydrogen content can be determined (see [15]). The time between the start of the measurement and the extraction from the cryo-container is usally less than $6 \mathrm{~min}$.

With regard to the binding energy, however, it should be noted that temperature dependent desorption behaviour also depends on the sample geometry, heating rate as well as on the diffusion behaviour of the material. Therefore, the obtained curves are not readily comparable to other data sources [18].

The established autoclave set-up was used to investigate the hydrogen uptake behaviour of the martensitic stainless steel 1.4418. Samples were exposed to hydrogen pressures of $1.1,6.7$ and $15 \mathrm{MPa}$ at a charging temperature of $250^{\circ} \mathrm{C}$. The given pressures were achieved after heating from room temperature to $250^{\circ} \mathrm{C}$. The initially at room temperature adjusted pressures were 1, 6 and $13.5 \mathrm{MPa}$ respectively. To capture the sorption behaviour dependent on the experimental conditions (temperature and pressure), different charging times at $250^{\circ} \mathrm{C}$ peak temperature were scheduled.

\section{Results and Discussion}

The samples were charged using the procedure described above. The realised parameters are compiled in Table 3 . As charging temperature, $250^{\circ} \mathrm{C}$ was chosen. The heating sleeve temperature was adjusted according to Figure 3 to $284^{\circ} \mathrm{C}$.

Each charging batch included three samples. After charging with hydrogen under the given conditions in Table 3, the samples were stored in a cryo-container for transportation and finally measured using thermal desorption spectroscopy. Figure 5 shows the TDS spectra of samples that were exposed for slightly more than $2.5 \mathrm{~h}$ to varying hydrogen pressures at $250^{\circ} \mathrm{C}$.

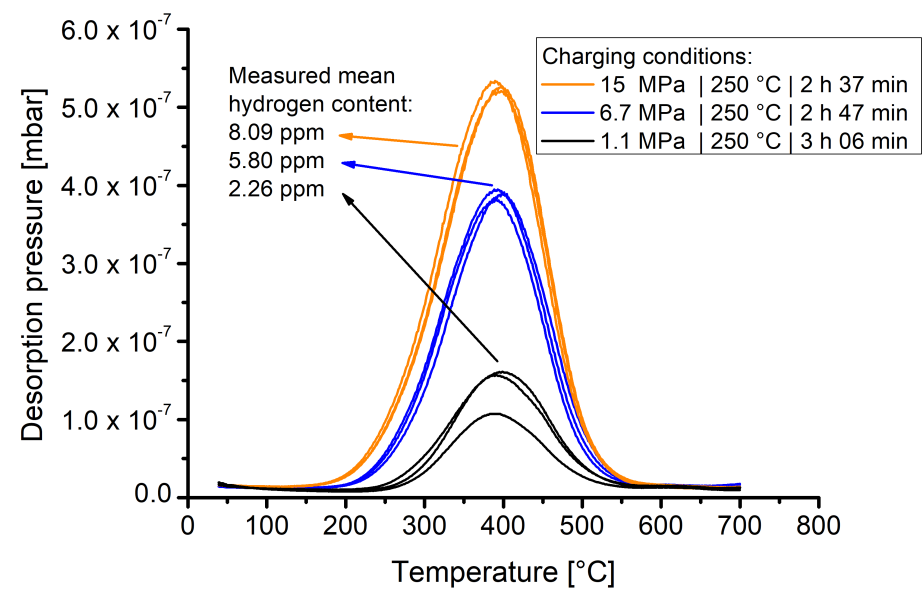

Figure 5. TDS spectra collected from samples that were exposed to gaseous hydrogen at $250^{\circ} \mathrm{C}$ at pressures of 1.1, 6.7 and $15 \mathrm{MPa}$ for given timespans.

The results show that material 1.4418 exhibits a markedly pressure dependent hydrogen solubility. The pressure dependent hydrogen contents are clearly differentiable and the experimental curves of one batch show good reproducibility.

Figure 6 shows the time and pressure dependent hydrogen contents that were obtained by the TDS measurements. The lines indicate the respective sorption curves. The sorption behaviour is dependent on the hydrogen diffusion coefficient. The latter was determined using the experimental data points. Therefore, the pressure dependent measurements were normalised to the respective hydrogen equilibrium contents (see Table 3), thus creating a kind of master curve. To obtain the hydrogen diffusion coefficient, a least squares fit was performed to fit Equation (1) to the data. 


$$
\frac{M_{t}}{M_{\infty}}=1-\sum_{n=1}^{\infty} \frac{4}{a^{2} \alpha_{n}^{2}} \cdot \exp \left(D \alpha_{n}^{2} t\right)
$$

where $M_{t}$ is the hydrogen content at time $t, M_{\infty}$ is the equilibrium hydrogen content, $\alpha_{n}$ is the $n$th zero of the Bessel function of 1 type and 0 order, $a$ is the radius and $D$ is the hydrogen diffusion coefficient [19].

The hydrogen diffusion coefficient determined with this procedure is $1.64 \times 10^{-10} \mathrm{~m}^{2} / \mathrm{s}$.

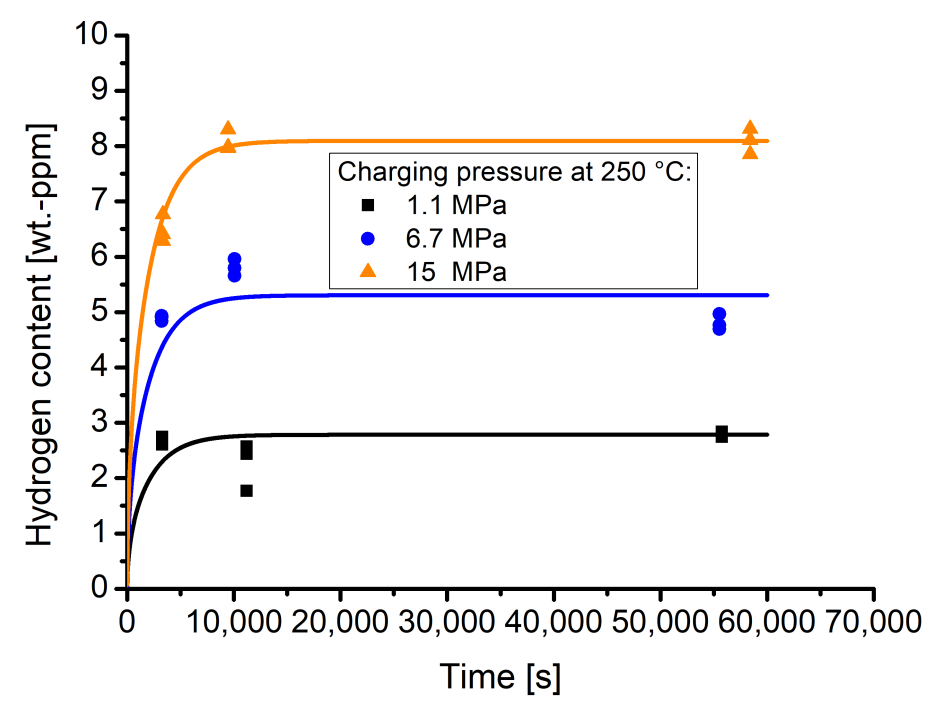

Figure 6. Time and pressure dependent hydrogen contents as well as sorption curves, calculated according to the estimated diffusion coefficient at $250^{\circ} \mathrm{C}$ of $\mathrm{D}=1.64 \times 10^{-10} \mathrm{~m}^{2} / \mathrm{s}$.

It can be seen that, for the highest pressures of $15 \mathrm{MPa}$, the time dependent hydrogen contents are well along the sorption curve, while for the pressures 6.7 and $1.1 \mathrm{MPa}$ deviations from the sorption curves are apparent. In the case of the values obtained for a pressure of $6.7 \mathrm{MPa}$ and for a time of approximately $2.5 \mathrm{~h}$, the measured hydrogen content is higher than that for longer holding times. In the case of $1.1 \mathrm{MPa}$, the hydrogen contents are lower at approximately $3 \mathrm{~h}$ holding than those obtained for approximately $1 \mathrm{~h}$ holding time. The deviations might be attributed to effects that arise due to the fact that the measurements were performed with certain time intervals in between. It cannot be completely ruled out that the calibration constant of the TDS device experiences a drift. Furthermore, other effects that arise due to the storage within the cryo-container might also influence the hydrogen contents that are maintained within the samples. Nevertheless, due to the measured hydrogen contents at $250^{\circ} \mathrm{C}$ with different pressures, the experiments are well suited to describe the hydrogen sorption behaviour of material 1.4418.

Furthermore, the hydrogen contents measured in material 1.4418 can be classified well with data for other materials from the literature [20,21], as displayed in Figure 7 . The values obtained for the nickel martensitic stainless steel are significantly higher than for a quenched and tempered low alloyed CrMo-steel, but still below values reported for austentic steels of the 300 series. The material SUS630 is a nickel martensitic precipitation hardened alloy. Due to its chemical composition, it can be assumed that the hydrogen content soluble in this material should be comparable to the one in material 1.4418 of the underlying investigation. As shown in Figure 7, this is the case and the values are plausible in comparison to the other material classes as well as in agreement with expectations. 


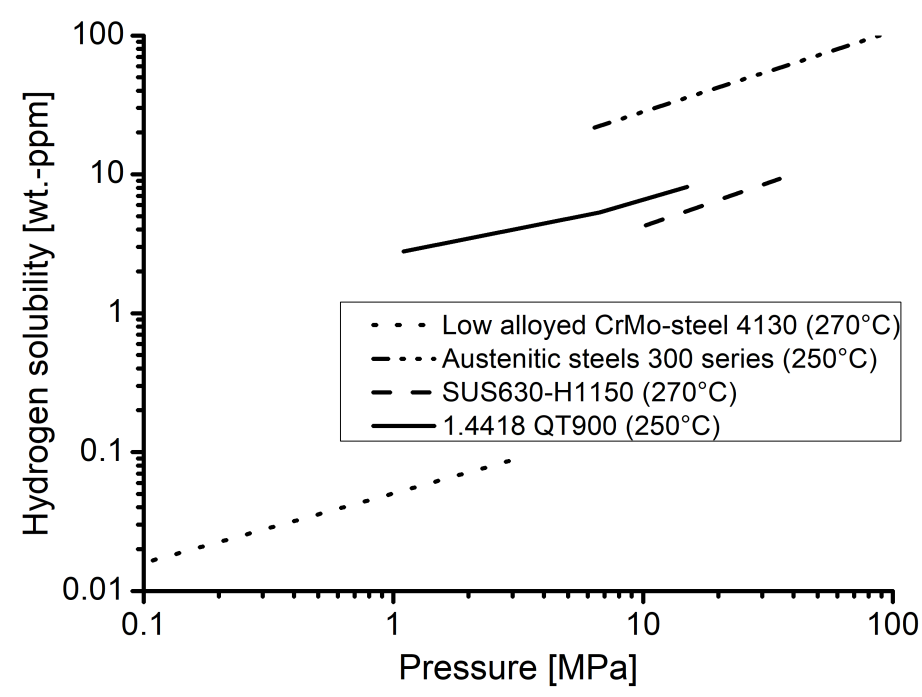

Figure 7. Hydrogen solubilities of the material 1.4418 in comparison to those for austenitic stainless steels [20] (both at $250{ }^{\circ} \mathrm{C}$ ), a nickel martensitic maraging steel SUS630-H1150 [20] and a low alloyed CrMo-steel [21] (both at $270^{\circ} \mathrm{C}$ ).

The values determined for the hydrogen diffusion coefficient can be classified similarly with regard to the data from literature. Figure 8 shows the diffusion coefficients of material 1.4418 at room temperature [10] and at $250^{\circ} \mathrm{C}$ from the underlying investigation, together with scatterbands for austenitic as well as ferritic and martensitic steels [12] and for selected alloys.

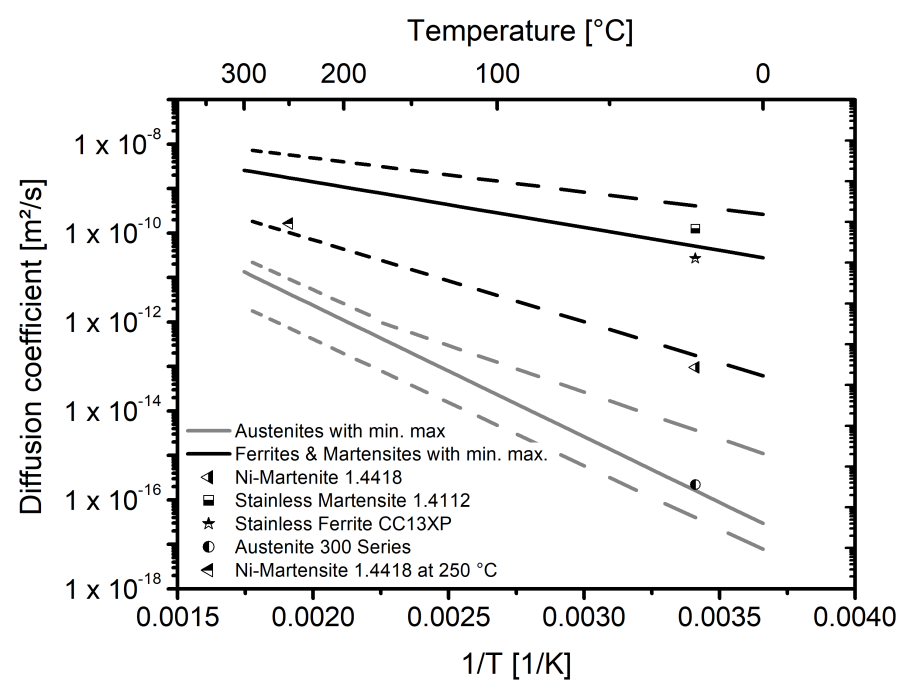

Figure 8. Temperature dependent diffusion coefficients. Scatterbands for austenitic, ferritic and martensitic steels are taken from [12], diffusion coefficients at room temperature for steels 1.4418, 1.4112 and CC13XP are taken from [10] and the Data for the austenites of the 300 series are taken from [22]. The data point for the steel 1.4418 at $250{ }^{\circ} \mathrm{C}$ is from the underlying investigation.

The steel 1.4418 exhibits a diffusion coefficient which is at the lower end of the scatterband for the ferritic/martensitic steels. This is true for the coefficient determined with an electrochemical double-cell as well as for the coefficient determined at $250^{\circ} \mathrm{C}$ with gaseous hydrogen. In agreement with the hydrogen solubilities for the different alloy classes, the diffusion coefficient can also be classified to be between the ferritic/martensitic steels and the austenitic steels.

The investigated hydrogen solubilities and the calculated hydrogen diffusion furthermore are in support of the materials remarkable hydrogen compatibility in $1 \mathrm{MPa}$ hydrogen atmosphere. This is at least in part explainable due to the fact that mechanisms describing 
hydrogen environment embrittlement as, e.g., the hydrogen-enhanced-localised-plasticity mechanism (HELP) [4] are dependent on the materials hydrogen diffusivity.

The underlying paper presents a method to study the temperature and pressure dependent hydrogen solubility of materials. Advantageous are the uncomplicated handling of the autoclave set-up as well as its agile thermal behaviour including the possibility to rapidly load and unload samples. The short handling times reduce the hydrogen egress from samples that might occur when dealing with larger autoclave devices. Hydrogen egress might only occur during the cooling phase of the autoclave and shortly before the TDS measurements are started due to the fact that the samples need to be defrosted and a certain pressure needs to be achieved within the measurement apparatus.

It was further shown that the hydrogen content in material 1.4418 is high compared to low alloyed steels. In agreement with that, the hydrogen diffusivity is comparably low, thus supporting the good hydrogen compatibility under consideration of the relatively high material strength. Hydrogen compatibility can often be correlated with the diffusion and solubility behaviour of a material, due to the fact that mechanisms discussed in the literature, e.g., the HELP mechanism [4], are dependent on the materials hydrogen diffusivity.

For material 1.4418, a clear pressure dependency of the hydrogen solubility was observed. The batch measurements showed a good reproducibility and the overall behaviour showed the suitability of the approach to study the sorption behaviour as well as the hydrogen equilibrium contents.

The equilibrium hydrogen contents as well as the evaluated diffusion coefficient can be classified well to data from the literature. In comparison to other material classes as well as to the material behaviour at room temperature, it has to be mentioned, however, that the calculation of the diffusion behaviour at $250^{\circ} \mathrm{C}$ is based on the assumption that no surface reactions (e.g., adsorption, dissociation or recombination) are rate limiting but the only determining factor describing the sorption behaviour is the bulk diffusion of the material.

At lower temperatures, hydrogen reactions with the surface such adsorption, dissociation and absorption might become rate limiting, with a respective effect on the hydrogen sorption behaviour. These effects can be investigated by comparing to diffusion coefficients obtained by measurements at high temperature as well as by electrochemical measurements at lower temperatures.

The methodology allows studying the solubilities and diffusivities of materials with significantly reduced times where hydrogen egress might occur especially in comparison to commonly larger autoclave setups. Furthermore, the diffusion behaviour can be studied based on the sorption behaviour. Although surface effects cannot be separated, the temperature, pressure and time dependent sorption behaviour can be quantified, which is very valuable, e.g., when it comes to a hydrogen pre-conditioning prior to mechanical (static or dynamic) testing.

Author Contributions: All authors have read and agreed to the published version of the manuscript.

Funding: The underlying research was partly financed by the publicly funded project MatHyP. Financial support was granted by the Federal Ministry for Economic Affairs and Energy of Germany under project number 03ETB006A.

Acknowledgments: The authors thank Michael Hirscher for the possibility to perform the TDS measurements at the Max Planck Institute for Intelligent Systems (MPI-IS) in Stuttgart (formerly Max Planck Institute for Metals Research). The underlying research was partly financed by the publicly funded project MatHyP. The authors acknowledge the financial support by the Federal Ministry for Economic Affairs and Energy of Germany in the project MatHyP (project number 03ETB006A). Furthermore, we thank Hans Willi Langenbahn, the Dean of Faculty of Process Engineering, Energy and Mechanical Systems of Technische Hochschule Köln, for financial assistance in publishing our research paper.

Conflicts of Interest: The authors declare no conflict of interest. 


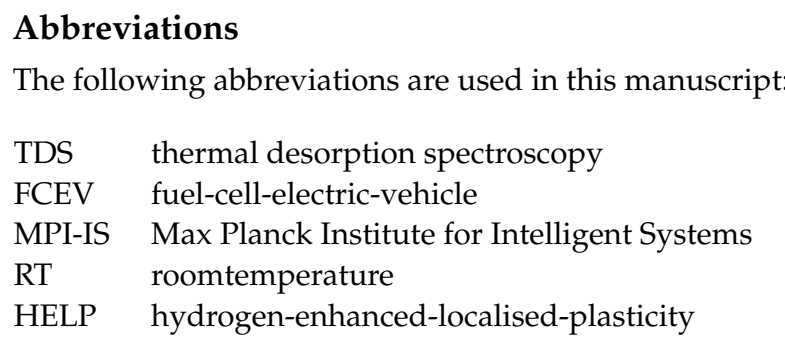

\section{References}

1. Züttel, A. Hydrogen storage methods. Die Nat. 2004, 91, 157-172. [CrossRef] [PubMed]

2. Staffell, I.; Scamman, D.; Abad, A.V.; Balcombe, P.; Dodds, P.E.; Ekins, P.; Shah, N.; Ward, K.R. The role of hydrogen and fuel cells in the global energy system. Energy Environ. Sci. 2019, 12, 463-491. [CrossRef]

3. Schick, N. Referenz-Brennstoffzellensystem für Elektrofahrzeuge. MTZ-Mot. Z. 2019, 80, 100-104. [CrossRef]

4. Robertson, I.; Sofronis, P.; Nagao, A.; Martin, M.L.; Wang, S.; Gross, D.W.; Nygren, K.E. Hydrogen embrittlement understood. Metall. Mater. Trans. B 2015, 46, 1085-1103. [CrossRef]

5. Takai, K.; Shoda, H.; Suzuki, H.; Nagumoc, M. Lattice defects dominating hydrogen-related failure of metals. Acta Mater. 2008, 56, 5158-5167. [CrossRef]

6. Lynch, S. Hydrogen embrittlement (HE) phenomena and mechanisms. In Stress Corrosion Cracking; Elsevier: Amsterdam, The Netherlands, 2011; pp. 90-130.

7. Möser, M.; Schmidt, V. Fractography and mechanism of hydrogen cracking-the fisheye concept. In Fracture 84; Elsevier: Amsterdam, The Netherlands, 1984; pp. 2459-2466.

8. Fujita, F. The role of hydrogen in the fracture of iron and steel. Trans. Jpn. Inst. Met. 1976, 17, 232-238. [CrossRef]

9. Michler, T.; Naumann, J. Influence of high pressure hydrogen on the tensile and fatigue properties of a high strength $\mathrm{Cu}-\mathrm{Al}-\mathrm{Ni}-\mathrm{Fe}$ alloy. Int. J. Hydrogen Energy 2010, 35, 11373-11377. [CrossRef]

10. Schauer, G. Auslegungsansatz für Stahlbauteile bei Ermüdungsbeanspruchung in Druckwasserstoffatmosphäre. Ph.D. Thesis, Universität Stuttgart, Stuttgart, Germany, 2018.

11. San Marchi, C.; Michler, T.; Nibur, K.A.; Somerday, B.P. On the physical differences between tensile testing of type 304 and 316 austenitic stainless steels with internal hydrogen and in external hydrogen. Int. J. Hydrogen Energy 2010, 35, 9736-9745. [CrossRef]

12. Boellinghaus, T.; Hoffmeister, H.; Dangeleit, A. A scatterband for hydrogen diffusion coefficients in microalloyed and low carbon structural steels. Weld. World/Le Soudage Monde 1995, 2, 149.

13. Zafra, A.; Peral, L.B.; Belzunce, J.; Rodriguez, C. Effect of hydrogen on the tensile properties of $42 \mathrm{CrMo} 4$ steel quenched and tempered at different temperatures. Int. J. Hydrogen Energy 2018, 43, 9068-9082. [CrossRef]

14. Peral, L.B.; Zafra, A.; Blason, S.; Rodriguez, C.; Belzunce, J. Effect of hydrogen on the fatigue crack growth rate of quenched and tempered CrMo and CrMoV steels. Int. J. Fatigue 2019, 120, 201-214. [CrossRef]

15. Zeppelin, F.; Haluska, M.; Hirscher, M. Thermal desorption spectroscopy as a quantative tool to determine the hydrogen content in solids. Thermochim. Acta 2003, 404, 251-258. [CrossRef]

16. Schubert, A. MatFuel-Werkstofftechnik für Brennstoffzellenkomponenten-Förderkennzeichen BMWi 03ET2051A. Robert Bosch GmbH 2017. Available online: https:/ / www.tib.eu/de/suchen/id/TIBKAT:895006367?cHash=052e6876f2a939af01bf4d872 7097562 (accessed on 11 September 2020).

17. Escobar, D.P.; Verbeken, K.; Duprez, L.; Verhaegea, M. Evaluation of hydrogen trapping in high strength steels by thermal desorption spectroscopy. Mater. Sci. Eng. A 2012, 551, 50-58. [CrossRef]

18. Frappart, S.; Oudriss, A.; Feaugas, X.; Creus, J.; Bouhattate, J.; Thébault, F.; Delattre, L.; Marchebois, H. Hydrogen trapping in martensitic steel investigated using electrochemical permeation and thermal desorption spectroscopy. Scr. Mater. 2011, 65, 859-862.

19. Crank, J. The Mathematics of Diffusion; Oxford University Press: Oxford, UK, 1975.

20. Yamabe, J.; Awane, T.; Takakuwa, O.; Matsuoka, S. Hydrogen-assisted degradation of high-strength stainless steel with a newly developed aluminum-based coating in high-pressure hydrogen gas environment. Press. Vessel. Pip. Conf. 2017, 58004, V06BT06A038.

21. Somerday, B.P. Technical References on Hydrogen Compatibility of Materials-Low-Alloy Ferritic Steels: Tempered Fe-CrMo Alloys (code 1211)—Sandia National Laboratories. Robert Bosch GmbH. Volume 551, pp. 50-58. Available online: https: / / www.sandia.gov/matlsTechRef/chapters/1211TechRef_FeCrMo_T.pdf (accessed on 26 June 2020).

22. American National Standards Institute. ANSI/CSA CHMC 1-2014 Test Methods for Evaluating Material Compatibility in Compressed Hydrogen Applications_-Metals; CSA Group: Toronto, ON, Canada, 2014. 